\title{
The effects of Clostridium difficile crude toxins and purified toxin A on stripped rabbit ileal mucosa in Ussing chambers
}

\author{
T. J. MITCHELL, J. M. KETLEY, D. W. BURDON*, D. C. A. CANDY $\dagger$ and J. STEPHEN
}

Department of Microbiology, University of Birmingham, P.O. Box 363, Birmingham B15 2TT, "The General Hospital, Steelhouse Lane, Birmingham B4 6NH and †Institute of Child Health, Francis Road, Birmingham B16 $8 E T$

\begin{abstract}
Summary. Clostridium difficile crude toxins and purified toxin A had similar effects on stripped rabbit ileal mucosa in Ussing chambers. Both toxin preparations caused secretion of sodium and chloride ions by increasing serosa to mucosa $(s \rightarrow m)$ fluxes. Transmural potential difference and resistance decreased after toxin treatment. Onset of changes in electrical measurements and ion fluxes coincided with onset of histological changes. The response to theophylline was greatly reduced in toxintreated tissue compared with control tissue.
\end{abstract}

\section{Introduction}

Clostridium difficile is the primary aetiological agent of antibiotic-associated pseudomembranous colitis and some cases of antibiotic-associated diarrhoea (Bartlett et al., 1978; George et al., 1978). In some patients $C$. difficile induces watery diarrhoea with no apparent mucosal damage (Mogg et al., 1979). In this paper, we consider possible mechanisms and determinants of this watery diarrhoea against a background (briefly summarised below) of current knowledge on $C$. difficile toxinology.

We recently discussed (Mitchell et al., 1986) the range and properties of known toxins produced by $C$. difficile that are of possible relevance in the causation of diarrhoeal disease. These include (1) toxin A (enterotoxin), and (2) toxin B (cytotoxin), on the nature and properties of which there is a considerable body of evidence from several laboratories. In addition, from individual laboratories there exist largely unconfirmed reports of (3) a motility-altering factor, (4) a labile toxin that induces a clear fluid accumulation in rabbit ileal loops, and (5) a low-mol.-wt subunit toxin "active in rabbit ileal loops" (but uncharacterised in terms of the nature of the exsorbed fluid and induction of tissue damage). The current controversy concerning C. difficile toxins arising from the use of a latex test

Received 12 May 1986; accepted 10 Jun. 1986.

Correspondence should be sent to Dr J. Stephen, Department of Microbiology, University of Birmingham, Birmingham B15 2TT. for C. difficile toxin A (Lyerly and Wilkins, 1986) is as yet unresolved.

There are at least three possibilities to explain watery fluid secretion by $C$. difficile. First, Lonnroth and Lange (1983) claimed that toxin A induces a watery secretion in mouse ileal loops and that a combination of toxins $\mathrm{A}$ and $\mathrm{B}$ produces a haemorrhagic response in this model. This is certainly not the case in rabbit ileum and hamster caecum - the two most widely used models in this field-in which toxin $\mathrm{A}$ on its own induces tissue damage and a haemorrhagic fluid response; at present it is not clear whether this reflects genuine differences in response by different species to toxin $A$.

Second, Banno et al. (1984) reported a labile toxin that produced a watery fluid response in the rabbit ileal loop test. However, in our laboratory, only one of numerous attempts was successful in repeating the findings of Banno and co-workers. The relevance of this factor therefore remains unresolved.

Third, it is our view that toxin $A$, which we have shown to be of overriding importance in the causation of tissue damage and fluid accumulation in rabbit experimental systems (Mitchell et al., 1986) could be responsible. Such a view is confirmed by Lyerly et al. (1985) who showed that toxin A was responsible for the enteric effects of toxic crude culture filtrates administered orogastrically to hamsters. The apparently high mol. wt of toxin A (Taylor et al., 1981) makes the concept of a multifunctional molecule capable of inducing fluid secretion, tissue damage, or both, inherently possi- 
ble. The watery diarrhoea without tissue damage could ensue when, for whatever reason, only one aspect of its biological activity was expressed. Alternatively, toxin A may be a monofunctional entity that acts in a progressive manner on susceptible tissues, inducing first a watery secretory diarrhoea which is then masked or swamped by the later effects of gross tissue damage. If, for any reason, this progression is impeded early in the attack upon susceptible tissue, watery diarrhoea could ensue.

There are at least two studies that bear on the possibility of a $C$. difficile-induced secretory diarrhoea. Vesely et al. (1983) showed that both toxins A and B elevated levels of guanylate cyclase in hamster colon, ileum and duodenum; cyclic GMP is a known secretogogue. Hughes et al. (1983) claimed that crude $C$. difficile culture filtrate blocked sodium absorption and stimulated chloride secretion. This response was not associated with a change in transmural potential difference. Cyclic nucleotide levels were similar to those in control tissues but the response was found to be dependent on $\mathrm{Ca}^{2+}$. Changes in ion transport occurred in the absence of any overt tissue damage. These workers proposed that a $C$. difficile factor was the first known example of an enterotoxin that caused secretion by a $\mathrm{Ca}^{2+}$-mediated mechanism.

The aim of the present study was to determine whether, within the first few hours of exposure, $C$. difficile crude culture filtrate or purified toxin A affected intestinal transport in rabbit ileum with or without the tissue damage we have previously observed in vivo (Mitchell et al., 1986) and in vitro (Stephen et al., 1984). To maximise the possibility of dissecting primary from subsequent events, we have examined the effect of toxin $A$ on stripped rabbit ileal mucosa.

\section{Materials and methods}

\section{Toxin production and purification}

C. difficile strain B-1 (supplied by Dr S. P. Borriello, Clinical Research Centre, Harrow) was grown in $1 \mathrm{~L}$ of saline inside a dialysis bag suspended in $7 \mathrm{~L}$ of the medium previously described by Stephen et al. (1984). After growth at $37^{\circ} \mathrm{C}$ for 4 days the culture was clarified by centrifugation $\left(25000 \mathrm{~g}, 30 \mathrm{~min}, 4^{\circ} \mathrm{C}\right)$. This crude material was sterilised by passage through a $0.22 \mu \mathrm{m}$ pore size membrane filter (Millipore) and stored at $4^{\circ} \mathrm{C}$.

Toxin A was purified from crude material as previously described (Stephen et al., 1984) by ammonium sulphate precipitation, preparative electrophoresis and ion exchange chromatography.

\section{ELISA}

An ELISA procedure, as described by Redmond et al. (1985) was used to enable crude and purified preparations with similar toxin A contents to be compared.

\section{Ion transport studies}

Unidirectional ion fluxes were determined by the modified method of Isaacs et al. (1976). Male New Zealand white rabbits were killed by administration of a sodium pentobarbital overdose $(60 \mathrm{mg} / \mathrm{kg}) ; 30 \mathrm{~cm}$ of distal ileum was removed, opened along its mesenteric border and placed in oxygenated Ringer solution $\left(\mathrm{Na}^{+}\right.$ $148 \mathrm{mM}, \mathrm{Cl}^{-} 125 \mathrm{mM}, \mathrm{K}^{+} 4.3 \mathrm{mM}, \mathrm{HCO}_{3}{ }^{-} 26 \mathrm{mM}, \mathrm{Ca}^{2+}$ $1.2 \mathrm{mM}, \mathrm{H}_{2} \mathrm{PO}_{4}{ }^{-1} 1.2 \mathrm{mM}, \mathrm{Mg}^{2+} 1.2 \mathrm{mM}$ and glucose $10 \mathrm{mM}$ ). The mucosa from segments of ileum was stripped from the muscle layers by blunt dissection and mounted between two halves of a perspex tissue chamber (Ussing chamber). The tissue was bathed on both sides by $10 \mathrm{ml}$ of Ringer solution. The buffer was circulated and oxygenated by a gas lift mechanism (Schultz and Zalusky, 1964) with $\mathrm{CO}_{2} 5 \%$ in oxygen. The system was maintained at $37^{\circ} \mathrm{C}$ by a constant-temperature water jacket.

All electrical measurements and manipulations were done with an automatic voltage clamp. The electrical apparatus was connected to the tissue chamber with saltagar bridges (agar $4 \%$ in Ringer solution). Potential difference (PD) measurements were made with matched calomel electrodes (Chemetric Ltd, Sherborne, Dorset) immersed in $3 \mathrm{M} \mathrm{KCl}$. Short-circuit conditions were achieved by applying current via silver-silver chloride electrodes (Clark Electrochemical Instruments Ltd, Reading) immersed in $0.15 \mathrm{M} \mathrm{NaCl}$, and the short-circuit conditions were maintained by an electronic feedback circuit. Corrections were made for the drop in PD between the PD electrodes caused by the resistance of the fluid between the tips of the measuring bridges and the tissue. This resistance was determined before mounting the tissue. The automatic voltage clamp contained a special circuit for making the correction based on the calculated value for fluid resistance. Tissue resistance was expressed as the quotient obtained by dividing the open circuit PD by the short circuit current (SCC).

Sodium and chloride fluxes were measured with paired tissues from the same segment of ileum. Tissues were not paired unless their electrical resistances were comparable and differed by less than $25 \%$. One hour after mounting the tissue, crude toxin containing $100 \mu \mathrm{g}$ of toxin A (determined by ELISA), or $100 \mu \mathrm{g}$ of purified toxin A, was introduced into the mucosal side of the chambers. In control experiments, no toxin was added. ${ }^{22} \mathrm{Na} 2 \mu \mathrm{Ci}$ and ${ }^{36} \mathrm{Cl} 2 \cdot 3 \mu \mathrm{Ci}$ (Amersham International) were then introduced on the mucosal side of one tissue of a pair and on the serosal side of the other. Samples of the Ringer solution from the labelled and unlabelled sides of the chambers were taken every $20 \mathrm{~min}$ for $2 \mathrm{~h}$. At the time of sampling, the open circuit PD was recorded. Two separate $1-\mathrm{ml}$ samples were taken at each time point, one for gamma counting and the other for liquid scintillation counting. Sample volumes were replaced with unlabelled 
buffer. ${ }^{22} \mathrm{Na}$ in each sample was determined by gamma counting and total radioactivity by liquid scintillation counting with ACSII liquid scintillation cocktail (Amersham International). The activity for ${ }^{22} \mathrm{Na}$ multiplied by a factor for the relative efficiency of the two counters for ${ }^{22} \mathrm{Na}$ was subtracted from the total radioactivity to yield the counts due to ${ }^{36} \mathrm{Cl}$. Unidirectional and net ion fluxes were calculated by the method of Isaacs et al. (1976).

Statistical analysis of the flux data was by a paired $t$ test. All fluxes from tissues treated with either crude or pure toxin were compared with fluxes at their equivalent control time points. For example, $\mathrm{Na}^{+} \mathrm{M} \rightarrow \mathrm{S}$ flux at $100 \mathrm{~min}$ from control tissue was used for comparison of flux data from tissue treated with either crude or purified toxin at $100 \mathrm{~min}$. Thus, significance is ascribed to values that are significantly different from controls at the given time points, but not necessarily different from zero.

\section{Theophylline response}

At the end of experiments, $1 \mathrm{ml}$ of $100 \mathrm{~mm}$ theophylline was added (giving a final concentration of $10 \mathrm{mM}$ ) to the serosal side of the chambers and the change in open circuit PD noted.

\section{Histology}

After various incubation times, tissue was removed from the chambers and fixed in formaldehyde $(4 \%$ in saline). Samples were embedded in paraffin wax, sectioned and stained with haematoxylin and eosin for examination by light microscopy.

\section{Results}

\section{Electrical response}

Addition of either crude toxins or purified toxin A had similar effects. After a lag period of approximately $80 \mathrm{~min}$ each preparation caused a steady decline in transmural PD and tissue resistance (fig. 1). Short-circuit current declined slightly but was not significantly different from that of the control (data not shown).

\section{Ion fluxes}

In control tissue, net sodium absorption occurred at all time points (fig. 2). Exposure to either crude or purified toxin A caused net secretion of sodium ions beginning after approximately $80 \mathrm{~min}$ and increasing with time of incubation. Statistical analysis indicated that sodium fluxes were significantly different from control values after incubation for $100 \mathrm{~min}$ with toxin.

Analysis of unidirectional sodium fluxes showed that $\mathrm{m} \rightarrow \mathrm{s}$ transport was not significantly different from that of controls. Net ion outflow was due to an increase in the $s \rightarrow m$ flux.

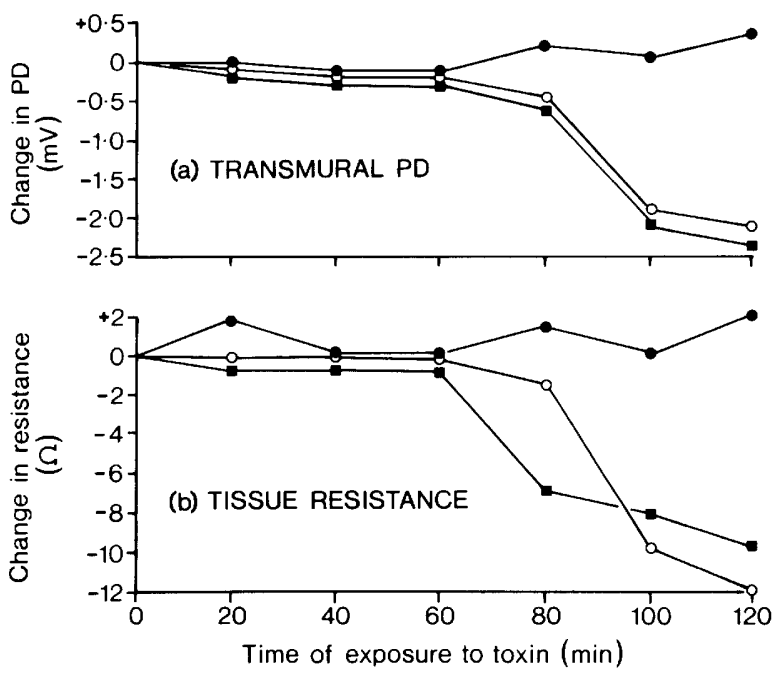

Fig. 1. The effects of $C$. difficile toxins added to the mucosal side on (a) transmural potential difference (PD) and (b) tissue resistance across stripped rabbit ileum mounted in Ussing chambers.

Control; $\mathrm{O}-\mathrm{O}$ crude toxins containing toxin $\mathrm{A}$ $10 \mu \mathrm{g} / \mathrm{ml}$ and toxin B $10^{5}$ units $/ \mathrm{ml}$ (final concentrations in chamber); - purified toxin A $10 \mu \mathrm{g} / \mathrm{ml}$ (final concentration in chamber). Data are the means of 12 determinations.

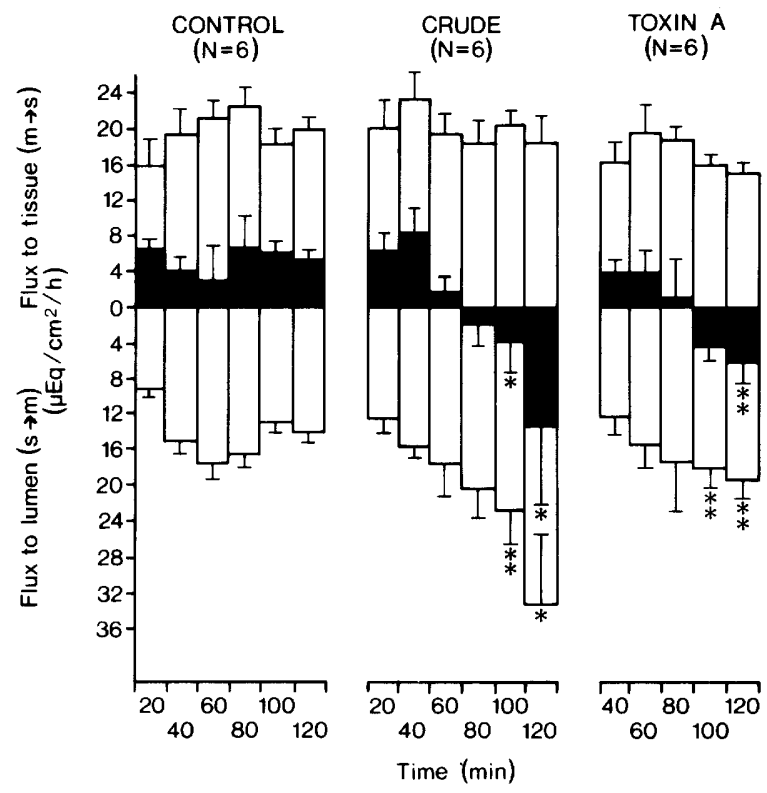

Fig. 2. Effect of $C$. difficile toxins on unidirectional (open bars) and net (solid bars) sodium fluxes across stripped rabbit ileum in Ussing chambers. Crude toxins were added to the mucosal side of tissues such that the final concentration of toxin $A$ was $10 \mu \mathrm{g} / \mathrm{ml}$ and that of toxin B was $10^{5}$ units $/ \mathrm{ml}$. Purified toxin A was added to the mucosal side of tissues to a final concentration of $10 \mu \mathrm{g} / \mathrm{ml}$. Data are the means of six determinations and error bars represent SEM; * $\mathrm{p}<0.05,{ }_{*}^{*} \mathrm{p}<0.01$. 
Toxin treatment also caused a reversal of chloride transport from net absorption in controls to net secretion beginning at approximately $80 \mathrm{~min}$ in toxin-treated tissue (fig. 3). Secretion of chloride was also due to an increase in the $s \rightarrow m$ flux; the $\mathrm{m} \rightarrow \mathrm{s}$ flux was not significantly different from that of controls. Statistical analysis indicated that chloride fluxes were significantly different from control values after incubation for $120 \mathrm{~min}$ with the toxin. The net rate of chloride secretion was always exceeded by the rate of sodium secretion in toxintreated tissue.

\section{Theophylline response}

The response of tissue to theophylline was reduced after 2 -h exposure to the toxin (table).

\section{Histology}

Examination of toxin-treated tissue showed that histological changes had occurred by $80 \mathrm{~min}$. The changes included denudation of villus tips by desquamation of enterocytes and extrusion of cellular components from the lamina propria. Crypt areas appeared to be unaffected by the toxin (see Ketley et al., 1987).

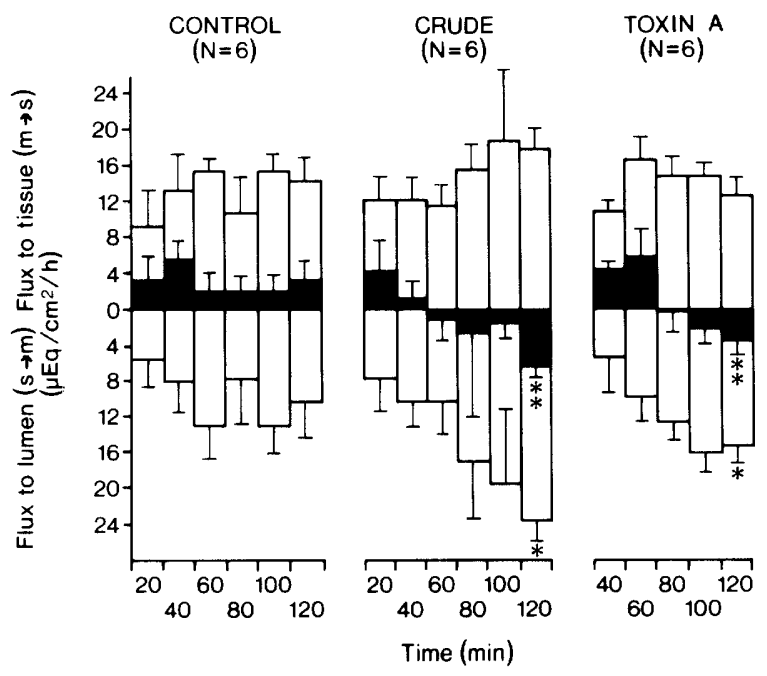

Fig. 3. Effect of $C$. difficile toxins on unidirectional (open bars) and net (solid bars) chloride fluxes across stripped rabbit ileum in Ussing chambers. Crude toxins were added to the mucosal side of the tissue such that the final concentration of toxin A was $10 \mu \mathrm{g} / \mathrm{ml}$ and that of toxin B was $10^{5}$ units $/ \mathrm{ml}$. Purified toxin A was added to the mucosal side of tissues to a final concentration of $10 \mu \mathrm{g} / \mathrm{ml}$. Data are the means of six determinations and error bars represent the SEM.*p $<0.05,{ }_{*}^{*} p<0 \cdot 02$.

\section{Discussion}

In this study, toxin A caused an apparent secretion of electrolytes but this was found to be associated with histological changes. Changes in transmural potential difference (PD) and short circuit current (SCC) can only be confidently interpreted in terms of altered active transport when tissue resistance remains fairly constant; tissue resistance is the electrical measurement reflecting tissue integrity. In our experiments, tissue resistance always fell; the onset of the fall correlated with the onset of histological changes to the architecture of the villus tips. In a preliminary study (Stephen et al., 1984), we reported a rise in SCC when toxin A was added to the mucosal side of stripped rabbit ileal mucosa mounted in Ussing chambers in which the tissue was bathed in salt solutions without glucose. Subsequent work showed that the rise in SCC was most likely to be due to a change in tissue resistance during a period when the transmural PD generated under such conditions was reasonably constant and comparatively low $(0.8 \mathrm{mV})$.

Examination of ion fluxes indicated that crude or purified toxin A caused a net secretion of both sodium and chloride beginning at approximately $80 \mathrm{~min}$. The secretion of both ions was due to increased $\mathrm{s} \rightarrow \mathrm{m}$ flux. The rate of sodium secretion exceeded the rate of chloride secretion at all time points.

There are two possible mechanisms by which toxin A could induce an increase in the $s \rightarrow m$ flux resulting in a net outflow of sodium ions. First, the toxin could stimulate an active secretory pathway; or second, the toxin could induce changes in ion fluxes that are primarily due to toxin-induced

Table . Effect of $C$. difficile toxins on the response of isolated rabbit ileum to $10 \mathrm{~mm}$ theophylline after incubation for $2 \mathrm{~h}$

Test preparation*

Response to $10 \mathrm{~mm}$ theophylline $(\mathrm{mV})$
Control $(\mathrm{N}=20)$
$2 \cdot 15 \pm 0 \cdot 20$
Crude toxins: final concentrations- toxin A $10 \mu \mathrm{g} / \mathrm{ml}$, toxin B $10^{5}$ units/ $\mathrm{ml}(\mathrm{N}=20)$
Purified toxin A: final concentration $10 \mu \mathrm{g} / \mathrm{ml}(\mathrm{N}=8)$

$$
\begin{aligned}
& 0.74 \pm 0.08 \\
& 0.41 \pm 0.16
\end{aligned}
$$

*After incubation for $2 \mathrm{~h}$ in the Ussing chamber, theophylline was added to the serosal reservoir to a final concentration of $10 \mathrm{~mm}$. The change in open circuit potential difference $(\mathrm{mV})$ was noted. $\mathrm{N}=$ number of observations. Errors are expressed as SEM. 
changes in the structure, i.e., in the permeability of the tissue. The total resistance of ileal tissue is determined mainly by the low-resistance paracellular pathway (Frizzell and Schultz, 1972). Hence, in the absence of evidence to the contrary, any changes in tissue resistance would be likely to reflect changes in this pathway. If the net secretion of sodium is due to changes in the paracellular pathway (affecting the diffusion of sodium) then there must be a mechanism to impose directionality on this transport process. This is discussed in the following paragraphs.

An effect of toxin A on the paracellular pathway could lead to net sodium secretion as follows. The current model for normal sodium transport involves absorption of sodium by villus cells across their apical membranes. The sodium is then extruded into the intercellular spaces by $\mathrm{Na}^{+} \mathrm{K}^{+}$ATPase. This would result in high levels of sodium ions within the intercellular spaces. Normally, sodium exit into the lumen is restricted by the tight junctions and sodium ions are retained on the tissue side. Toxin-induced damage to the tight junctions could change the permeability to sodium and allow movement of sodium down its electrochemical gradient to the mucosal side of the tissue. This electrochemical gradient exists within, rather than across the tissue and would not necessarily be eliminated by short-circuit conditions. The existence of electrochemical gradients within the tissue (even under short-circuit conditions) is often overlooked in the interpretation of data from Ussing chamber experiments.

It is not possible to state dogmatically from the available data whether sodium secretion induced by toxin $\mathrm{A}$ is due to stimulation of an active mechanism or to changes in tissue structure. However, it seems highly likely that it is due to the latter because it occurs after histological changes are apparent; these changes are also probably responsible for the fall in transmural PD.

Chloride ions are also secreted in response to toxin A. Again it is not clear whether the toxin is activating an active secretory mechanism or chloride ions are moving passively with sodium ions. The fact that chloride fluxes do not become significantly different from control values until 20 min after sodium fluxes suggests that chloride may be moving passively; this is the preferred explanation.

Several other cytotoxic enterotoxins cause changes in ion transport similar to those induced by toxin A. Rabbit ileum exposed to Shiga toxin for $5 \mathrm{~h}$ in vivo and then mounted in Ussing chambers had decreased transmural PD and tissue resistance and secreted sodium due to an increased $s \rightarrow m$ flux. The change in $\mathrm{m} \rightarrow \mathrm{s}$ sodium transport was not significant, even though glucose transport was reduced (Donowitz et al., 1975). C. perfringens enterotoxin also caused secretion of sodium ions in the perfused rat ileum due to an increase in $\mathrm{s} \rightarrow \mathrm{m}$ flux (McDonel and Asano, 1975); there was no change in the $\mathrm{m} \rightarrow \mathrm{s}$ flux, even though the toxin had previously been shown to inhibit glucose uptake (McDonel, 1974). As both of these toxins cause histological changes and perturb ion transport in a manner similar to that of toxin A, it appears that structural changes to the intestinal tissue may be responsible for the secretion induced by these toxins.

Tissue exposed to toxin $\mathrm{A}$ in the Ussing chamber was less responsive to theophylline than control tissues; the response was reduced by approximately $80 \%$ by treatment with purified toxin $\mathrm{A}$ for $2 \mathrm{~h}$. Theophylline normally causes a rise in transmural PD by raising the level of cAMP in the tissue. There are several possible reasons for the lack of theophylline response in toxin A-treated tissue. First, cAMP levels could already be raised in the tissue. This is the reason proposed for the lack of response of tissue which has been exposed to cholera toxin (Field et al., 1972). Second, adenylate cyclase could be inactivated by the toxin with the consequent inability of the tissue to synthesise cAMP (Vesely et al., 1981). Third, tissue damage may have decreased tissue viability and prevented the physiological response to theophylline. However, Shiga toxin caused marked histological damage but the tissue remained responsive to theophylline (Donowitz et al., 1975). The reason for the lack of theophylline response in tissue treated with toxin $A$ is unclear and requires further study.

$C$. difficile does not appear to produce or induce a true secretogogue as judged by the electrical and flux data presented here. This contrasts with the data of Hughes et al. (1983) who claimed that crude culture filtrates of $C$. difficile induced changes in ion transport across stripped rabbit ileum in the absence of histological damage.

The interaction of toxin A with ileum thus seems to have several stages. First, the toxin disrupts the epithelial cell layer, leading to a transient secretion of electrolytes which we think depends on the existence of paracellular electrochemical gradients; this could give rise to watery diarrhoea. Ion secretion would stop when these gradients were dissipated and hence watery fluid secretion would be transient and rapidly swamped by the subsequent bloody fluid secretion characteristic of toxin Atreated ileal loops (Mitchell et al., 1986). 
This work raises at least two further questions. First, how does toxin A affect enterocytes, because their perturbation or removal seems to be an essential prerequisite for fluid secretion? Attempts to elucidate this point are described by Mitchell $e t$ al. (1987a). Second, since no mechanism has yet been found that would explain a sustained (as opposed to a transient) watery diarrhoea induced by toxin $\mathrm{A}$ in distal rabbit ileum, should more work be done to explain the watery fluid secretion in toxin-treated colon previously described by Mitch-

\section{REFERENCES}

Banno Y, Kobayashi T, Kono H, Watanabe K, Ueno K, Nozawa Y 1984 Biochemical characterization and biologic actions of two toxins (D-1 and D-2) from Clostridium difficile. Reviews of Infectious Diseases 6 Suppl: S11-S20.

Bartlett J G, Moon N, Chang T W, Taylor N S, Onderdonk A B 1978 Role of Clostridium difficile in antibiotic-associated pseudomembranous colitis. Gastroenterology 75:778-782.

Donowitz M, Keusch G T, Binder H J 1975 Effect of Shigella enterotoxin on electrolyte transport in rabbit ileum. Gastroenterology $69: 1230-1237$.

Field M, Fromm D, Al-Awqati Q, Greenough W B 1972 Effect of cholera enterotoxin on ion transport across isolated ileal mucosa. Journal of Clinical Investigation 51 : 796-804.

Frizzell R A, SchultzS G 1972 Ionic conductances of extracellular shunt pathway in rabbit ileum. Influence of shunt on transmural sodium transport and electrical potential differences. Journal of General Physiology 59:318-346.

George R H et al. 1978 Identification of Clostridium difficile as a cause of pseudomembranous colitis. British Medical Journal 1:695.

Hughes S, Warhurst G, Turnberg L A, Higgs N B, Giugliano L G, Drasar B S 1983 Clostridium difficile toxin-induced intestinal secretion in rabbit ileum in vitro. Gut 24:94-98.

Isaacs P E T, Corbett C L, Riley A K, Hawker P C, Turnberg L A 1976 In-vitro behaviour of human intestinal mucosa. The influence of acetylcholine on ion transport. Journal of Clinical Investigation 58:535-542.

Ketley J M, Mitchell T J, Candy D C A, Burdon D W, Stephen J 1987 The effects of Clostridium difficile crude toxins and toxin A on ileal and colonic loops in immune and nonimmune rabbits. Journal of Medical Microbiology 23:199204.

Lonnroth I, Lange S 1983 Toxin A of Clostridium difficile: production, purification and effect in mouse intestine. Acta Pathologica et Microbiologica Scandinavica B 91 : 395-400.

Lyerly D M, Saum K E, MacDonald D K, Wilkins T D 1985 Effects of Clostridium difficile toxins given intragastrically to animals. Infection and Immunity 47:349-352.

Lyerly D M, Wilkins T D 1986 Commercial latex test for Clostridium difficile Toxin A does not detect toxin A. Journal of Clinical Microbiology 23:622-623. ell et al. (1986)? Such an attempt has been made by Mitchell et al. (1987b).

JS, DWB and DCAC thank Pfizer Central Research and the Science and Education Research Council for a CASE studentship awarded to TJM and the Medical Research Council for a studentship awarded to JMK. We warmly thank G. Hollins (Department of Medical Physics, Maternity Hospital, Birmingham) for the design and construction of the automatic voltage clamps; and Drs C J Lote (Department of Physiology, University of Birmingham) and I W Booth (Institute of Child Health, University of Birmingham) for generous help and discussions concerning the use of Ussing chambers.

McDonel J L 1974 In vivo effects of Clostridium perfringens enteropathogenic factors on the rat ileum. Infection and Immunity 10: 1156-1162.

McDonel J L, Asano T 1975 Analysis of unidirectional fluxes of sodium during diarrhea induced by Clostridium perfringens enterotoxin in the rat terminal ileum. Infection and Immunity 11: $526-529$.

Mitchell T J et al. 1986 The effect of toxin A and toxin B of Clostridium difficile on rabbit ileum and colon. Gut 27:7885.

Mitchell T J, Ketley J M, Burdon D W, Candy D C A, Stephen J $1987 a$ The effects of Clostridium difficile toxins A and B on membrane integrity and protein synthesis in intestinal cells in vivo and in vitro and in McCoy cells in vitro. Journal of Medical Microbiology 23:199-204.

Mitchell T J, Ketley J M, Burdon D W, Candy D C A, Stephen J $1987 b$ Biological mode of action of Clostridium difficile toxin A : a novel enterotoxin. Journal of Medical Microbiology 23:199-204.

Mogg G A G et al. 1979 Antibiotic-associated colitis-a review of 66 cases. British Journal of Surgery 66:738-742.

Redmond S C, Ketley J M, Mitchell T J, Stephen J, Burdon D W, Candy D C A 1985 Detection of Clostridium difficile enterotoxin. In: Collins C H, Grange J M (eds) Isolation and identification of micro-organisms of medical and veterinary importance (Society of Applied Bacteriology, Symposium Series no. 21) Academic Press, London, pp 237-250.

Schultz S G, Zalusky R 1964 Ion transport in isolated rabbit ileum. I. Short circuit current and $\mathrm{Na}$ fluxes. Journal of General Physiology 47:567-584.

Stephen J et al. 1984 Clostridium difficile enterotoxin (toxin A): new results. Biochemical Society Transactions 12: 194-195.

Taylor N S, Thorne G M, Bartlett J G 1981 Comparison of two toxins produced by Clostridium difficile. Infection and Immunity 34: 1036-1043.

Vesely D L, Straub K D, Nolan C M, Rolfe R D, Finegold S M, Monson T P 1981 Purified Clostridium difficile cytotoxin stimulates guanylate cyclase activity and inhibits adenylate cyclase activity. Infection and Immunity 33:285-291.

Vesely D L, Sullivan N M, Straub K D, Monson T P, Wilkins T D 1983 Clostridium difficile toxin A and toxin B both enhance guanylate cyclase activity. Clinical Research 31 : $378 \mathrm{~A}$. 